\title{
The Knee Tensegrity System Manages the Balance Between Tension and Compression
}

\author{
Wangdo Kim ${ }^{1 *}$ and Michael T Turvey ${ }^{2}$ \\ ${ }^{1}$ School of Mechanical and Aerospace Engineering, Seoul National University, Seoul Korea \\ ${ }^{2}$ Department of Psychology, University of Connecticut, USA
}

Submission: April 23, 2018; Published: October 17, 2018

*Corresponding author: Wangdo Kim, School of Mechanical and Aerospace Engineering, Seoul National University, Seoul Korea; Tel: +82-010-8644-2145; Email: mwdkim@gmail.com

\begin{abstract}
We characterize the concept of a "knee axis" and further the concept of "invariant." It is now generally recognized that one of the features of the tensegrity (prestressable to the same configuration) allows the knee tensegrity system to be in producing the knee instantaneous axis (KIA). We found that the line of the ground reaction force (GRF) vector is very close to the KIA. It aligns the knee joint with the GRF such that the reaction forces are torqueless. The reaction to the GRF will then be carried by the whole structures on the knee tensegrity instead. The use of knee tensegrity system introduces the new useful dimensions of sensitivity in foot loading to the knee axis alignment. This insight shows that locating KIA is equivalent to the dynamic alignment measurement. This method can be used for the optimal design of braces and orthoses for the conservative treatment of knee osteoarthritis.
\end{abstract}

Keywords: Knee tensegrity system; Knee instantaneous axis; The haptic perceptual system; Knee alignment

Abbreviations: Knee Instantaneous Axis (KIA); Ground Reaction Force (GRF); Center of Pressure (COP)

\section{Introduction}

The perceptual psychologist James J. Gibson regarded the senses as aggressively seeking mechanisms rather than mere passive receivers [1]. The active movement involves the concomitant operation of anatomical components, in which foot touch on the ground and rotation of the joints are combined, together with voluntary contractions of the muscles. The total flux of stimulation involved in the so-called active movement is enormously complex, but lawful modes of combination occur. Presumably, the modes of combination of these inputs specify the difference between touching (active) and being touched (passive) [2].

To identify the haptic system's medium Turvey focused on connective tissue and the conjunction of muscular, connective tissue net, and skeletal as the body's proper characterization [3]. Myers has also posed the medium as a body-wide responsive physiological network-the myofascial meridian [4]. Taking on 'geometry' first, cell biologist Donald Ingber placed one final piece of the puzzle: to view the body's architecture in the light of 'tensegrity' geometry [5]. 'Tensegrity' was coined from the phrase 'tension integrity' by the designer R. Buckminster Fuller (working from original structures developed by artist Kenneth Snelson [6].

The principle of tensegrity describes precisely the relationship between the connective tissues, the muscles, and the skeleton. Weight applied to shank/thigh bones would cause it to slide off its knee joint if it were not for the tensional balances that hold it in place and control its pivoting [7]. The invariant feature of tensegrity structures encompasses those that stabilize themselves through a phenomenon known as prestressing. Architects call this type of prestressed structural network, composed of opposing tension and compression elements that self-stabilizes its shape through the establishment of a mechanical force balance, a tensegrity (tensional integrity) structure. Biotensegrity is a term introduced by Dr. Stephen Levin and denotes the application of tensegrity's principles to biological structures [8].

Tensional forces naturally transmit themselves over the shortest distance between two points, so the elastic members of tensegrity structures are precisely positioned to best withstand applied stress. For this reason, tensegrity structures offer a maximum amount of strength for any given amount of material [4]. The invariant feature of a knee tensegrity system (specified by a given set of external forces such as the ground reaction force (GRF) is a stable equilibrium if the structure returns to the originally given configuration after the application of arbitrarily small perturbations with respect to the IKA anywhere within the configuration [5] (Figure 1).

Consequently, estimating of the knee axis is one of the key topics for the "2010 ASME Grand Challenge Competition to Predict In Vivo Knee Loads" [9]. Knee Functional Axes (KFA) information is referred to the knee instantaneous axis (KIA) [10-12]. In that case, the intersegmental force such as ligaments and contact forces are in pure tension/compression and are surrounding the KIA in such a way that those forces result in no (virtual) works [10]. 


\section{Journal of Yoga and Physiotherapy}

The objective of this study is to show how the knee tensegrity system manages the balance between tension and compression during locomotion by utilizing a unique combination of the KIA and GRF stimuli.

\section{Materials and Methods}

The intra-articular structures of the tensegrity system of the knee include the muscles, the anterior cruciate ligament (ACL), posterior cruciate ligament (PCL), medial collateral ligament (MCL), and articular contact in the medial $\left(\mathrm{P}_{1}\right)$ and lateral $\left(\mathrm{P}_{2}\right)$ compartments (Figure 1) [13]. We have shown that six constraints are members of the "joint reaction subspace (JRS)," and are spatially oriented in such ways that by imposing an internal tension or "prestress" to reduce the play in the system; this ensures immediate mechanical responsiveness (i.e., that movement of one element is felt by all others) and reduces impact fatigue at the joint.

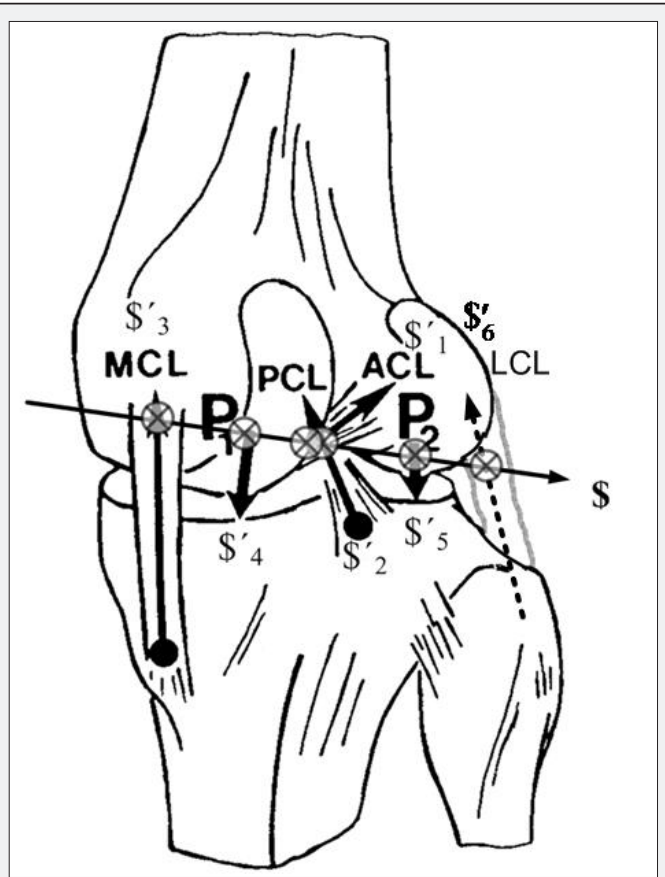

Figure 1: The tensegrity structure of surrounding forces applied to the knee joint: a native system of the knee where six constraints $\$$ ' are collectively reciprocal to the KIA $\$$ indicated by $\otimes$. That the virtual coefficient should vanish is necessary, and sufficient conditions $[15,16]$, or the pair ( $\$$ and $\$$ ') are in involution. The tensegrity's structure is characterized by the contact normal elements $\$_{4}^{\prime}$ and $\$_{5}^{\prime}$, while all the other elements are, continuous tension elements, showing specific configuration having torqueless connections.

\section{Results and Discussion}

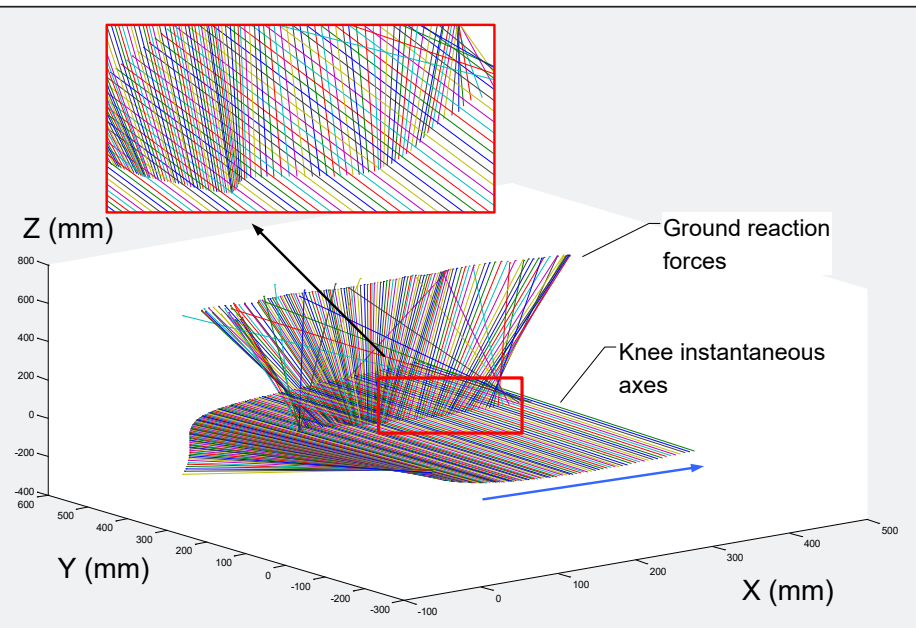

Figure 2: A unique combination of the KIA and GRF stimuli. When deformed by the shank to the ground via GRF, the strain is distributed over the whole structure, not localized in the area being deformed, i.e., the joint itself. A reaction torque is zero on the knee joint if the GRF line of action intersects the joint axis, or the configuration can exert a large force on the ground without overloading the knee joint. A considerable ground reaction force can be exerted on a foot when the vector nearly coincides with a reciprocal screw of joints. It is indicative of the "sense of support" being manifested based on the close correspondence of the vector of the ground reaction force at COP, and the IAK with fluctuations at the spatial scale of a millimeter (GRF-KIA coupling). 
We have measured the KIA through readily accessible benchmark data [9]. Also, we have measured the GRF on how the progression of the entire body over the limb uses so-called 'rockers' on foot. The issues of relating the reciprocal connection of the body framework to the movements of cutaneous kinesthesis [13-16] (Figure 2) enunciates that the body's haptic perceptual system registers the covariance of the KIA and GRF. The upward pressure on the surface of support on the ventral side of the foot provides, for every terrestrial animal, a continuous background of stimulation. It is covariant with the continuous input of the appropriate receptors of the articular motion in the knee joint already mentioned. Together they provide what the ordinary person calls the "sense of support."

A unique combination of invariants, a compound invariant, is just another invariant. It is a unit, and the components do not have to be combined or associated. Only if percepts were combinations of sensations would they have to be associated. Otherwise, we can postulate that when the KIA and GRF are completely covariant when they always go together, they constitute a single "stimulus". If the knee tensegrity system is capable of extracting invariants from a changing haptic stimuli, there is no reason why it should not extract invariants that seem to us highly complex. Therefore, the reaction torque caused by the foot-ground at the knee will be taken on partially by muscles surrounding the joint.

Perception is not based on the structure of force as it falls upon the plantar side of the foot, the erroneous theory of the passive, sense-datum theory, but on continuous modifications brought about by foot movement which cooperates with body posture to reveal its invariants-a surface of support. One of Gibson's more remarkable discoveries, coming out of his studies of ecological haptics, is the apparent paradox that some of the information that is encoded in our perceptions of the world is not given in sensation at all. Information essential for perception flows to the brain from proprioceptors (sensitive nerve-endings) in the joints and muscles. But it cannot be registered consciously as a feeling, or sensation, though it is quite essential to the identification of the structures that we do consciously experience and knowingly explore.

We need to establish a new paradigm for braces and orthoses intended to reduce the load that promises a beneficial effect. Is the aspect of unloading essential, or are stability and proprioception the most important factors? The question of the latter can be answered by the exploration of 'the tensegrity configuration of the knee.'

\section{References}

1. Gibson JJ (1962) Observations on active touch. Psychol Rev 69: 477491.

2. Gibson JJ (1966) The senses considered as perceptual systems. Houghton, USA.

3. Turvey MT, Fonseca ST (2014) The medium of haptic perception: a tensegrity hypothesis. J Mot Behav 46(3): 143-187.

4. Myers TW (2014) Anatomy trains: myofascial meridians for manual and movement therapists. Elsevier, Edinburgh, USA.

5. Ingber DE (1998) The architecture of life. Sci Am 278(1): 48-57.

6. Skelton RE, Oliveira MCd (2009) Tensegrity systems. Springer, New York, USA.

7. Swanson RL (2013) Biotensegrity: a unifying theory of biological architecture with applications to osteopathic practice, education, and research-a review and analysis. J Am Osteopath Assoc 113(1): 34-52.

8. Hutson MA, Ellis RM (2006) Textbook of musculoskeletal medicine. Oxford University Press, New York, USA.

9. Fregly BJ, Besier TF, Lloyd DG, Delp SL, Banks SA, et al. (2012) Grand challenge competition to predict in vivo knee loads. Journal of Orthopaedic Research 30(4): 503-513.

10. Kim W, Kim YH, Veloso AP, Kohles SS (2013) Tracking Knee Joint Functional Axes through Tikhonov Filtering and Plücker Coordinates. Journal of Novel Physiotherapies 4(1).

11. Kim W, Choi Y, Lee HG (2016) The Duality of Knee Functional Axes and Foot Contact. Journal of Functional Morphology and Kinesiology 1(4): 387.

12. Kim W, Choi Y, Lee HG (2016) Observations on the Knee Functional Axis During Active Movements. SM Musculoskeletal Disorders 1(1): 5.

13. Kim W, Veloso A, Tan J, Andrade C (2010) A Reciprocal Connection at Knee Joint. ASME 2010 Summer Bioengineering Conference, Naples, USA.

14. Kim W, Kohles SS (2011) A reciprocal connection factor for assessing knee-joint function. Computer Methods in Biomechanics and Biomedical Engineering 15(9): 911-917.

15. Kim W, Veloso AP, Araújo D, Vleck V, João F (2013) An informational framework to predict reaction of constraints using a reciprocally connected knee model. Computer Methods in Biomechanics and Biomedical Engineering 18(1): 78-89.

16. Kim W, Veloso AP, Vleck VE, Andrade C, Kohles SS (2013) The Stationary Configuration of the Knee. Journal of the American Podiatric Medical Association 103(2): 126-135. 
@ـ

This work is licensed under Creative Commons Attribution 4.0 License

DOI: 10.19080/JYP.2018.06.555690
Your next submission with Juniper Publishers will reach you the below assets

- Quality Editorial service

- Swift Peer Review

- Reprints availability

- E-prints Service

- Manuscript Podcast for convenient understanding

- Global attainment for your research

- Manuscript accessibility in different formats

( Pdf, E-pub, Full Text, Audio)

- Unceasing customer service

Track the below URL for one-step submission https://juniperpublishers.com/online-submission.php 